\title{
Determinants of Pneumonia in Children Aged Two Months to Five Years in Urban Areas of Oromia Zone, Amhara Region, Ethiopia
}

\author{
Abel Fekadu Dadi*, Yigzaw Kebede", Zelalem Birhanu ${ }^{\#}$ \\ Institute of Public Health, College of Medicine and Health Science, University of Gondar, Gondar, Ethiopia \\ Email: ${ }^{*}$ Fekten@yahoo.com, kyigzaw@yahoo.com, Zelalem78@gmail.com
}

Received 4 September 2014; revised 23 October 2014; accepted 25 November 2014

Copyright (C) 2014 by authors and OALib.

This work is licensed under the Creative Commons Attribution International License (CC BY).

http://creativecommons.org/licenses/by/4.0/

c) (i) Open Access

\begin{abstract}
Introduction: Out of fifteen countries that have the highest death rate from clinical pneumonia in children younger than five-year-old, Ethiopia ranks as number four in the world. Regardless of this fact, efforts to identify determinants of pneumonia have been limited in Ethiopia. This study identifies the risk factors of pneumonia in children aged two months to five years in urban areas of Oromia Zone, Amhara Region, Ethiopia. Methods: The researchers used an institutional-based unmatched case control study. All selected cases were identified through enumeration and control cases were identified systematically. The researchers used structured interviews, and observational and anthropometric measurements to collect the required information. Result: Data were actually collected from 121 cases and 235 controls. The risk of pneumonia was diminished among children in the 2 - 11 months age group (OR = 0.15, 95\%CI: 0.06, 0.36) and $12-23$ months age group $(\mathrm{OR}=0.38,95 \% \mathrm{CI}: 0.15,0.92)$ as compared to children in the $35-60$ months age group. An increased risk of pneumonia was associated with the father's primary education $(1-4)$ (AOR = $10.7,95 \% \mathrm{CI}: 2.69,42.7)$ and $(5-8)(\mathrm{AOR}=4.67,95 \% \mathrm{CI}: 1.2,17.9)$ as compared to higher education. Similarly, child cared by housekeeper and their relatives were at higher odds $(\mathrm{AOR}=2.79,95 \% \mathrm{CI}$ : $1.12,6.9$ ) of developing pneumonia as compared to child cared by their parents. Children's having, history of diarrhea (AOR $=3.06,95 \% \mathrm{CI}: 1.54,6.11$ ) and household history of acute lower respiratory infection (AOR $=3.04,95 \% \mathrm{CI}: 1.20,7.77$ ) respectively, were at higher odds of developing pneumonia compared to their counterpart. Conclusion: This study presents the independent predisposing factors of childcare practice, child history of diarrhea and household history of acute lower respiratory infection for the occurrence of pneumonia. Actions taken against the above risk factors may help to prevent pneumonia.
\end{abstract}

\section{Keywords}

Pneumonia, Determinant, Children Aged 2 Months to Five Years, Case Control Study

${ }^{*}$ Corresponding author.
${ }^{\#}$ This authors contribute equally to this work.

How to cite this paper: Dadi, A.F., Kebede, Y. and Birhanu, Z. (2014) Determinants of Pneumonia in Children Aged Two Months to Five Years in Urban Areas of Oromia Zone, Amhara Region, Ethiopia. Open Access Library Journal, 1 : e1044.

http://dx.doi.org/10.4236/oalib.1101044 


\section{Introduction}

Pneumonia is a major cause of mortality among children under five worldwide [1]. The incidence of pneumonia in children younger than five is 0.29 episodes per year. 151.8 million cases are recorded annually in developing countries. 4 million cases are recorded annually in developed countries. Fifteen countries contribute 74 percent of the world's annual pneumonia cases [2]. Half of the world's deaths caused by pneumonia in children younger than five occur in Africa [3]. In Sub-Saharan Africa, the anticipated proportion of deaths due to pneumonia in children younger than 5 is 17 - 26 percent [1]. In Ethiopia, Acute Respiratory Infections (ARI), otherwise known as severe pneumonia, is the third leading cause of outpatient visits (next to malaria and helminthiasis), and is one of the leading causes of mortality in children younger than five [4].

Out of fifteen countries that have the highest death rate from clinical pneumonia in children younger than five-year-old, Ethiopia ranks as number four in the world (84.6 deaths per 10,000 under five population) [5]. The Amhara region is one of the most affected regions in Ethiopia and accounts for 29.4 percent of ARI cases in children younger than five [6]. Approximately 13 percent of pneumonia cases are severe enough to necessitate hospitalization. 8.7 percent of pneumonia cases occurring in countries with high incidence are severe enough to be life threatening [2]. Severe pneumonia among children is connected with increased long-term respiratory morbidity and disease load. Understanding the epidemiology of severe pneumonia is a priority for public health research [7] [8].

Risk factors for pneumonia are categorized into three groups: definite (most evidence consistently pointing to the role of the risk factor); likely (most evidence consistently pointing to the role, but with some opposing findings; or scarce but consistent evidence of the role); and possible (with sporadic and inconsistent reports of the role in some contexts) [2]. Although Ethiopia has shown progress, respiratory illness remains the primary reason for the necessity of health services (27\%) [9]. To prevent respiratory symptoms and disease, physicians must look outside the healthcare sphere.

Pneumonia control efforts that target the major determinant factors are critical for those already affected. Researchers conducted this study to assess the determinants of pneumonia, adding newly implemented programs such as the urban health extension program and 10-valent pneumococcal conjugate vaccine synflorix ${ }^{\mathrm{TM}}$ as independent factors to help prevent pneumonia in children younger than five in urban areas of the Oromia zone.

\section{Method}

\subsection{Study Area}

The study area was in urban areas of Oromia zone, which is one of 11 zones of the Amhara regional state. There were seven urban town under zonal administration each had one primary health centers. Kemise, a capital town, is located $325 \mathrm{~km}$ northwest of Addis Ababa. The population of the zone is 510,295 people: 13 percent (66,553) are living in urban kebeles and 13.5 percent (8984) are children under five-year-old. According to zonal health department 2013 annual report, the potential health service coverage of the zonal administration reached 77\%.

\subsection{Study Design and Source Population}

Researchers employed an institutional-based unmatched case control study from 23 March 2013 to 23 April 2013. The source and study population consisted of children two months to five years in age living in urban kebeles of Oromia zone, Amhara Region. Researchers observed both cases and controls of children aged two months to five years who attended health institutions for different reason within the data collection period and who lived in urban kebeles for a minimum of six months.

\subsection{Cases}

The cases were children aged two months to five years positive for pneumonia as defined by the World Health Organization (WHO) Integrated Management of Childhood Illness (IMNCI) guideline adopted by Ethiopian Government since 2001. 
Typical pneumonia: an acute infection of the lungs with symptoms of coughing, fast breathing and chest in drawing.

\subsection{Controls}

Selected children aged two months to five years who presented for immunization and growth monitoring service.

\subsection{Operational Definition}

Household history of acute lower respiratory infection (ALRI): a household with a history of pneumonia or bronchitis in the last fifteen days prior to data collection.

House hold history of acute upper respiratory infection (AURI): a child whose family has a history of ear infection, common cold, tonsillitis, or pharyngitis in the last fifteen days prior to data collection.

\subsection{Sample Size Determination}

Researchers calculated the sample size using the STATCALC program and calculated the minimum number of cases and controls required by taking assumptions of a 95 percent confidence level, 90 percent power and 49.3 percent controls stunted giving OR of 2.23 [10]. Stunting was selected because it was the exposure variable that gave the highest sample size of cases and controls among the other variables from previous studies. Researchers used two controls for each case (122 cases and 244 controls).

\subsection{Sampling Technique}

Researchers included all seven health centers in urban kebeles, including the two town administrations implementing urban health extension programs. As a marker for proportional sample size allocation for health centers, researchers observed client flow of three consecutive previous months prior to the data collection period. Researchers used a systematic random sampling and enumeration method to select controls and cases. The first interviewer was selected using the lottery method (Figure 1).

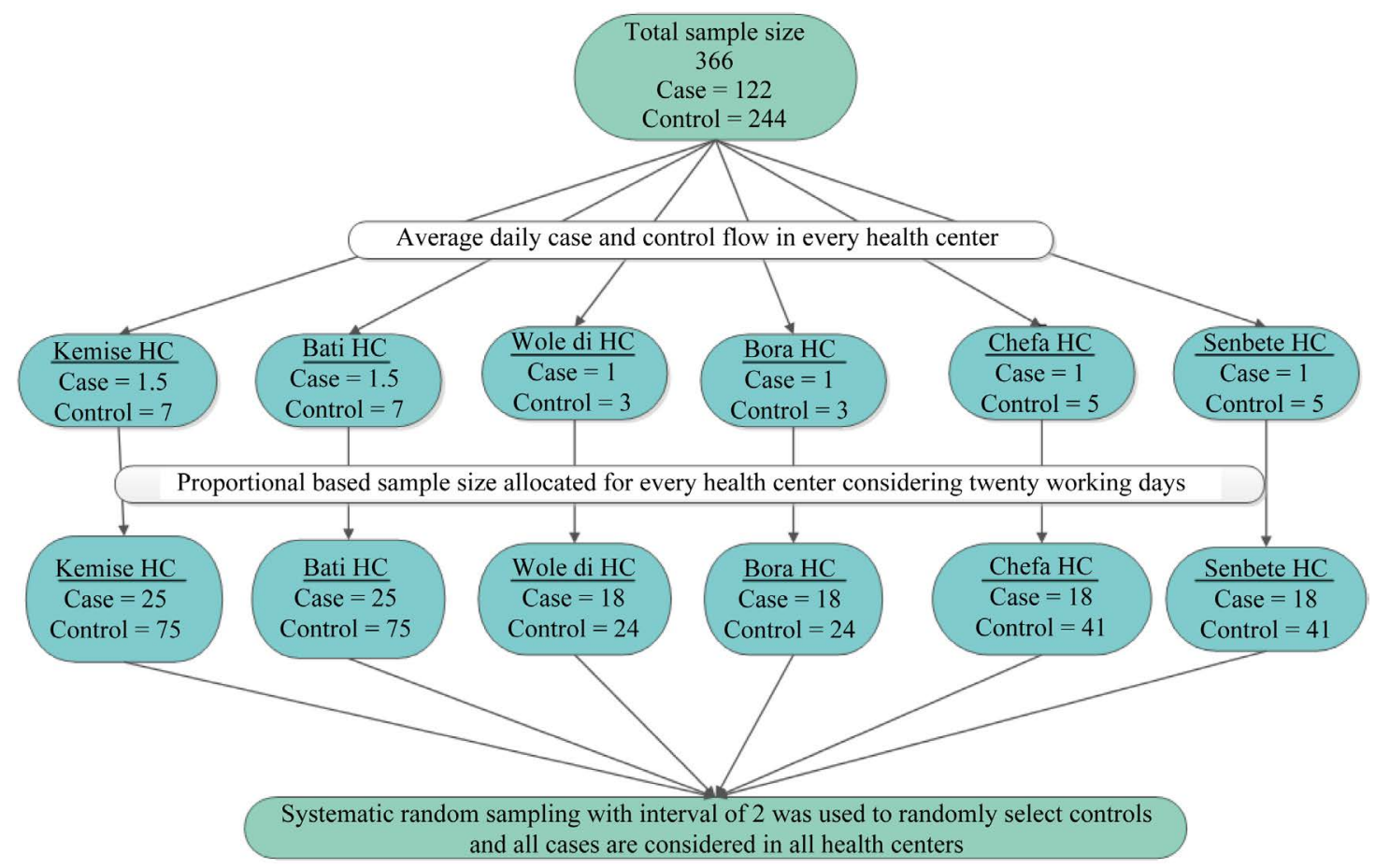

Figure 1. Shows sampling technique and sampling procedure for children's age from 2 months to 5 years in urban areas of Oromoia zone, April 24, 2013 ( $\mathrm{N}=121$ cases \& 235 controls). 


\section{Data Collection}

Parents of children aged two months to five years who were on-site during data collection were eligible to participate in the study.

Researchers used a pretested, structured Amharic questionnaire to collect information. Face-to-face interviews and document review was done to collect data on independent and socio demographic variables. Anthropometric measurements of height (to the nearest 0.1 centimeter) and weight (to the nearest 0.1 gram) of the children was taken. Nutritional status of the children was determined using Enhanced nutritional action (ENA) software. Researchers used the WHO (2006) growth standard to report principal anthropometric results, and the global acute malnutrition standard was used to categorize a child's condition as stunted, wasted or underweight.

\subsection{Data Quality Assurance}

Language experts translated the questionnaire from Amharic to English for consistency. Researchers conducted pretests on different sample areas by taking 10 percent of the total sample size and applying the questionnaire. Eighteen nurses underwent one day of training as data collectors prior to data collection, then checked questionnaires for completeness, and corrected errors.

\subsection{Data Analysis}

All data was checked, coded, entered and analyzed using SPSS version 16. Researchers checked the extent of outliers, the different statistical assumptions and the appropriate correction mechanisms prior to analysis. Association of each independent variable was assessed with binary logistic regression, and the strength of their association was computed by an unadjusted odds ratio.

Variables showing statistically significant associations with the outcome variables (up to $p=0.2$ ) were considered as potential risk factors of pneumonia and simultaneously subjected to stepwise multiple logistic regression models to determine the significant independent risk factor of pneumonia. A p-value $<0.05$ was considered statistically significant.

\subsection{Ethical Consideration}

The University of Gondar's Institute of Public Health Ethical Committee granted clearance for this study. Researchers obtained permission from regional, zonal and woreda health offices. All participant mothers and guardians gave verbal informed consent to participate in the study on behalf of their children. We didn't obtain written informed consent because we believed that the study was not pose any ethical and moral problem on the respondent and in addition to this majority of the respondents were illiterate to sign on the consent form. The participant consent was documented as Yes/No question to participate or not on the first page of the questioner. The interviewer was not proceed unless the respondent respond as YES to participate. The institutional review board approves the consent procedure.

\section{Results}

\subsection{Socio-Demographic Characteristics of the Respondents}

One hundred and twenty one cases and 235 controls of children aged 2 months to five years participated in the study, making the response rate 99 percent and 96.3 percent for cases and controls, respectively. The mean age of the child was 13.65 months $(S D \pm 11.13)$ and 6.87 months $(S D \pm 6.1)$ for cases and controls, respectively. 54.5 percent of cases and 48.5 percent of controls were male. The mean age of mothers was 27.07 years ( $S D \pm$ 5.46) and 26.64 years ( $S D \pm 4.68$ ) for cases and controls, respectively. More than half of the fathers received formal education for both cases (57\%) and controls (52.3\%) (Table 1).

\subsection{Child and Parental Characteristics of the Respondents}

Regarding nutritional status of the children 48.7 percent of cases and 95 (40.4\%) controls were stunted. Nineteen percent of cases and 12.3 percent of controls were underweight. Five point eight (5.8) percent of cases and 7.2 percent of controls were wasted. Majority of cases (95.8\%) and controls (97.9\%) were exclusively breast fed for 
Table 1. Socio-demographic characteristics of children's age from 2 months to 5 years in urban areas of Oromia zone, April 24, 2013 ( $N=121$ case \& 235 controls).

\begin{tabular}{|c|c|c|}
\hline \multirow{2}{*}{ Variables } & \multicolumn{2}{|c|}{ Pneumonia } \\
\hline & Case, No. (\%) & Control, No. (\%) \\
\hline \multicolumn{3}{|l|}{ Age of the child } \\
\hline 2 - 11 months & $64(52.8)$ & 209 (88.9) \\
\hline 12 - 27 months & $45(37.2)$ & $22(9.4)$ \\
\hline 28 - 60 months & $12(10.0)$ & $4(1.7)$ \\
\hline \multicolumn{3}{|l|}{ Sex of child } \\
\hline Male & $66(54.5)$ & $114(48.5)$ \\
\hline Female & $55(45.5)$ & $121(51.5)$ \\
\hline \multicolumn{3}{|l|}{ Age of the mother } \\
\hline $15-24$ & $36(29.7)$ & $68(28.9)$ \\
\hline $25-34$ & $70(57.8)$ & 148 (62.9) \\
\hline$>34$ & $15(12.5)$ & $19(8.2)$ \\
\hline \multicolumn{3}{|l|}{ HH monthly income } \\
\hline$<500$ & $34(28.1)$ & $46(19.6)$ \\
\hline $500-1500$ & $64(52.8)$ & $105(44.7)$ \\
\hline$>1500$ & $23(19.1)$ & $84(35.7)$ \\
\hline \multicolumn{3}{|l|}{ Educational status of mother } \\
\hline Not attend formal education & $71(58.7)$ & $134(57.1)$ \\
\hline Primary (1 - 4) & $24(19.8)$ & $25(10.7)$ \\
\hline Primary (5 - 8) & $18(14.8)$ & 37 (15.7) \\
\hline Secondary $(9-12)$ & $2(1.8)$ & $23(9.7)$ \\
\hline Higher education & $6(4.9)$ & $16(6.8)$ \\
\hline \multicolumn{3}{|l|}{ Educational status of father } \\
\hline Not attend formal education & $69(57.0)$ & $123(52.3)$ \\
\hline Primary $(1$ - 4) & $19(15.7)$ & $18(7.6)$ \\
\hline Primary (5 - 8) & $20(16.5)$ & $26(11.1)$ \\
\hline Secondary $(9-12)$ & $8(6.6)$ & $41(17.4)$ \\
\hline Higher education & $5(4.2)$ & 27 (11.6) \\
\hline
\end{tabular}

at least three months. Sixty-five (65) percent of cases and 28.9 percent of controls started complementary feeding at six months.

Eight of 121 cases and 2 of 235 controls lived in a household with a history of tuberculosis. Twenty-eight (28.9) percent of cases and 10.6 percent of controls had history of diarrhea. Nineteen point eight (19.8) percent of cases and 3.4 percent of controls, and 29.7 percent of cases and 11.1 percent of controls had a history of ALRI and AURI, respectively. Seven point four (7.4) percent of cases and 2.9 percent of controls had a history of parental asthma.

Regarding the vaccination statuses of children, the majority of cases 105 (86.7\%) and controls 213 (90.6\%) received at least one full dose of pentavalent vaccine. Fifty nine eligible cases and 36 controls received measles vaccines. Ninety-seven cases (80\%) and 200 controls (85\%) received one full dose of the pneumococcal conjugate vaccine. The majority of cases 103 (85\%) and controls 222 (94.5\%) were cared for by their parents (Table 2).

\subsection{Environmental Related Characteristics of the Respondents}

About half of the cases 71 (58.7\%) and the majority of controls 179 (76\%) live in a house with a roof made of corrugated iron sheet. The majority of cases 114 (94\%) and controls 220 (93.6\%) live in a house made of wood 
Table 2. Child and parental characteristics of children's age from 2 months to 5 years in urban areas of Oromia zone, April 24, 2013 ( $\mathrm{N}=121$ case \& 235 controls).

\begin{tabular}{|c|c|c|}
\hline \multirow{2}{*}{ Variables } & \multicolumn{2}{|c|}{ Pneumonia } \\
\hline & Case, No. (\%) & Control, No. (\%) \\
\hline \multicolumn{3}{|l|}{ Nutritional status height for age } \\
\hline Stunted & $59(48.7)$ & $95(40.4)$ \\
\hline Not stunted & $62(51.3)$ & $140(59.6)$ \\
\hline \multicolumn{3}{|l|}{ Weight for age } \\
\hline Underweight & $24(19.8)$ & $29(12.3)$ \\
\hline Normal & $97(80.1)$ & $206(87.7)$ \\
\hline \multicolumn{3}{|l|}{ Weight for height } \\
\hline Wasted & $7(5.8)$ & $17(7.2)$ \\
\hline Not wasted & $114(94.2)$ & $218(92.8)$ \\
\hline \multicolumn{3}{|l|}{ HH Tb illness history } \\
\hline Yes & $8(6.6)$ & $2(0.8)$ \\
\hline No & $113(93.4)$ & $233(99.2)$ \\
\hline \multicolumn{3}{|l|}{ Breast feeding history } \\
\hline Exclusively BF for at least three months & $116(95.8)$ & 230 (97.9) \\
\hline Not exclusively BF & $5(4.2)$ & $5(2.1)$ \\
\hline \multicolumn{3}{|l|}{ Complementary feeding } \\
\hline Yes & $79(65.3)$ & $68(28.9)$ \\
\hline No & $14(11.6)$ & $26(11.1)$ \\
\hline Age less than 6months & $28(23.1)$ & $141(60.0)$ \\
\hline \multicolumn{3}{|l|}{ Pentavalent vaccine } \\
\hline Not vaccinated & $16(13.2)$ & $22(9.4)$ \\
\hline Take two dose & $34(28.1)$ & 148 (62.9) \\
\hline Take full dose & $71(58.7)$ & 65 (27.7) \\
\hline \multicolumn{3}{|l|}{ Get measles vaccine } \\
\hline Yes & $59(48.8)$ & 36 (15.3) \\
\hline No & $62(51.2)$ & 199 (84.7) \\
\hline \multicolumn{3}{|l|}{ PCV vaccine } \\
\hline Not vaccinated & 24 (19.8) & 35 (14.9) \\
\hline Take two dose & 35 (28.9) & $142(60.4)$ \\
\hline Take full dose & $62(51.3)$ & $58(24.7)$ \\
\hline \multicolumn{3}{|l|}{ Illness of diarrhea } \\
\hline Yes & 35 (28.9) & 25 (10.6) \\
\hline No & $86(71.1)$ & $210(89.4)$ \\
\hline \multicolumn{3}{|l|}{ Illness of measles } \\
\hline Yes & $1(0.8)$ & $2(0.8)$ \\
\hline No & $120(99.2)$ & $233(99.2)$ \\
\hline \multicolumn{3}{|l|}{ History of ALRI } \\
\hline Yes & 24 (19.8) & $8(3.4)$ \\
\hline No & $97(80.2)$ & 227 (96.6) \\
\hline \multicolumn{3}{|l|}{ History of AURI } \\
\hline Yes & $36(29.8)$ & $26(11.1)$ \\
\hline No & $85(70.2)$ & 209 (88.9) \\
\hline \multicolumn{3}{|l|}{ Parental asthma } \\
\hline Yes & $9(7.4)$ & $7(3.0)$ \\
\hline No & $112(92.6)$ & $228(97.0)$ \\
\hline \multicolumn{3}{|l|}{ Child caring practice } \\
\hline Parental & $103(85.1)$ & 222 (94.5) \\
\hline Home maid & 18 (14.9) & $13(5.5)$ \\
\hline
\end{tabular}


and mud. Ninety-two (76\%) cases and 161 (68.5\%) controls live in a house with a terra firma floor. Nearly half of both cases and controls live in crowded houses (Table 3).

\subsection{Factors Associated with Pneumonia}

In the bi-variable logistic regression analysis, variables such as age, parental education, vaccination status, childcare practice, housing condition and monthly income appeared to be associated with the rate of reduction of pneumonia and augmented risks of pneumonia. Child feeding at six months, child history of tuberculosis in the household, child diarrhea history, household history of AURI, ALRI and history of child carried on the back had a 0.05 significance level.

To identify independent determinant factors of pneumonia in children between two months and five years, researchers used five explanatory variables: child's age, father's education, child's diarrhea history, household history of ALRI and childcare practice.

Table 3. Environmental characteristics of children's age from 2 months to 5 years in urban areas of Oromia zone, April 24, 2013 ( $N=121$ case \& 235 controls).

\begin{tabular}{|c|c|c|}
\hline \multirow{2}{*}{ Variables } & \multicolumn{2}{|c|}{ Pneumonia } \\
\hline & Case, No. (\%) & Control, No. (\%) \\
\hline \multicolumn{3}{|l|}{ Main material of roof } \\
\hline Thatched & $50(41.3)$ & $56(23.8)$ \\
\hline Corrugated iron & $71(58.7)$ & $179(76.2)$ \\
\hline \multicolumn{3}{|l|}{ Main material of wall } \\
\hline Wood with mud & $114(94.2)$ & $220(93.6)$ \\
\hline Cement/brick & $7(5.8)$ & $15(6.4)$ \\
\hline \multicolumn{3}{|l|}{ Main material of floor } \\
\hline Earth & $92(7.6)$ & $161(68.5)$ \\
\hline Cement/brick & $29(92.4)$ & $74(31.5)$ \\
\hline \multicolumn{3}{|l|}{ Crowding status } \\
\hline Crowded & $68(56.2)$ & 115 (48.9) \\
\hline Not crowded & $53(43.8)$ & $120(51.1)$ \\
\hline \multicolumn{3}{|l|}{ Place of cooking } \\
\hline In the living room & $36(29.8)$ & $52(43.0)$ \\
\hline In the kitchen & $85(70.2)$ & $183(57.0)$ \\
\hline \multicolumn{3}{|c|}{ Child carried on the back during cooking } \\
\hline Yes & $39(32.2)$ & $51(21.7)$ \\
\hline No & $82(67.8)$ & $184(78.3)$ \\
\hline \multicolumn{3}{|l|}{ UHEP HH status } \\
\hline Trained and graduated & $54(44.6)$ & $112(47.7)$ \\
\hline On training & $53(43.8)$ & $60(25.5)$ \\
\hline Not packaged & $14(11.6)$ & $63(26.8)$ \\
\hline \multicolumn{3}{|c|}{ HH cigarette smoking practice } \\
\hline Yes & $27(22.3)$ & $48(20.4)$ \\
\hline No & $94(77.7)$ & $187(79.6)$ \\
\hline \multicolumn{3}{|c|}{ Proper hand washing practice of the $\mathrm{HH}$} \\
\hline Good & $55(45.5)$ & $105(44.7)$ \\
\hline Satisfactory & $58(47.9)$ & $99(42.1)$ \\
\hline Poor & $8(6.6)$ & $31(13.2)$ \\
\hline
\end{tabular}




\section{Discussion}

Pneumonia in children under five years of age is a leading cause of morbidity and mortality in Ethiopia and other developing countries [3]. Identifying risk factors for childhood pneumonia that are preventable is important to public health. This study identifies those preventable risk factors.

A child age 2 - 11 months and 12 - 23 months is85 percent (OR $=0.15,95 \% C I$ : $0.06,0.36)$ and 62 percent $(\mathrm{OR}=0.38,95 \% \mathrm{CI}: 0.15,0.92)$ more likely to develop pneumonia compared to a child in the same age category of 34 - 60 months. This finding contrasts to a study conducted elsewhere [11] [12], which reports an inverse relationship between children and the occurrence of pneumonia. One possible explanation for this contrasting finding might be the introduction of pneumococcal vaccine to children aged 1 - 25 months [13]-[15] (Table 4).

A father's literacy has an impact on childhood pneumonia; a higher-class level resulted in a diminished risk of pneumonia. A child whose father did not finish primary school $(1-4)$ and $(5-8)$ is 10.7 (AOR $=10.7$, 95\%CI: 2.69, 42.7) and 4.67 (AOR $=4.67,95 \% \mathrm{CI}: 1.2,17.9$ ) times more likely to develop pneumonia as compared to child whose father received higher education. This result correlates with a study conducted in different areas [11] [15] [16] (Table 4).

Children who were cared for by housekeepers were 2.79 (AOR $=2.79,95 \%$ CI: $1.12,6.9$ ) times more likely to develop pneumonia compared to children cared for by their parents. This result is supported by different studies in other places that report mothers who act as primary care providers reduce the risk of pneumonia in children [12] [16] [17] (Table 4).

Children from households with a history of ALRI within the past fifteen days prior to data collection were 3.04 (AOR $=3.06,95 \% \mathrm{CI}: 1.54,6.11)$ times more likely to develop pneumonia compared to their counterparts.

Table 4. Factors associated with pneumonia using bi-variable and multivariable logistic regression of children aged 2 months to 5 years in urban areas of Oromia zone, April 24, 2013 ( $\mathrm{N}=121$ case and 235 controls).

\begin{tabular}{|c|c|c|c|c|}
\hline \multirow{2}{*}{ Explanatory variable } & \multicolumn{2}{|c|}{ Pneumonia } & \multirow{2}{*}{$\mathrm{OR}_{\mathrm{c}}, 95 \% \mathrm{CI}$} & \multirow{2}{*}{$\mathrm{OR}_{\mathrm{A}}, \mathbf{9 5 \%} \mathrm{CI}$} \\
\hline & Case & Control & & \\
\hline \multicolumn{5}{|l|}{ Age (months) } \\
\hline $2-11$ & 29 & 142 & $0.12(0.05,0.26)^{*}$ & $0.15(0.06,0.36)^{*}$ \\
\hline $12-23$ & 35 & 67 & $0.29(0.13,0.67)^{*}$ & $0.38(0.15,0.92)^{*}$ \\
\hline $24-34$ & 36 & 14 & $1.47(0.57,3.76)$ & $1.92(0.68,5.35)$ \\
\hline $35-60$ & 21 & 12 & 1 & 1 \\
\hline \multicolumn{5}{|l|}{ Father's education status } \\
\hline No formal education & 69 & 123 & $3.03(1.12,8.22)^{*}$ & $3.11(0.95,10.15)$ \\
\hline Primary (1 - 4) & 19 & 18 & $5.7(1.80,18.00)^{*}$ & $10.70(2.69,42.70)^{*}$ \\
\hline Primary (5 - 8) & 20 & 26 & $4.15(1.35,12.70)^{*}$ & $4.67(1.20,17.90)^{*}$ \\
\hline Secondary $(9-12)$ & 8 & 41 & $1.05(0.31,3.56)$ & $0.88(0.21,3.77)$ \\
\hline Higher education & 5 & 27 & 1 & 1 \\
\hline \multicolumn{5}{|c|}{ Child diarrhea in last fifteen days } \\
\hline Yes & 35 & 25 & $3.42(1.93,6.00)^{*}$ & $3.06(1.54,6.11)^{*}$ \\
\hline No & 86 & 210 & 1 & 1 \\
\hline \multicolumn{5}{|c|}{ House hold history ALRI in last 15 days } \\
\hline Yes & 24 & 8 & $7.02(3.04,16.20)^{*}$ & $3.04(1.20,7.77)^{*}$ \\
\hline No & 97 & 227 & 1 & 1 \\
\hline \multicolumn{5}{|c|}{ Family child caring practice } \\
\hline Parental care & 103 & 222 & 1 & 1 \\
\hline Home maid & 18 & 13 & $2.98(1.41,6.32)^{*}$ & $2.79(1.12,6.90)^{*}$ \\
\hline
\end{tabular}

*Significant at $\mathrm{p}<0.05$. Note: Hosmer and lemeshow's goodness of model test was found to be chi-square of 2.7 with p-value of 0.91 which implies the goodness of the model to predict the outcome. 
The probable explanation to this result might be that respiratory tract infections are easily transmitted from household contacts to children. Severity of the disease also depends on virulence and load of the pathogen; the load is usually higher when infection is from a household contact [18] (Table 4).

Children who had history of diarrhea in the past fifteen days were 3.06 (AOR $=3.06,95 \%$ CI: $1.54,6.11$ ) times more likely to develop pneumonia compared to their counterparts. This result is supported by a study from Iraq, Zimbabwe and Tigray, Ethiopia [16] [19] [20]. Children who have a concomitant illness like diarrhea may have a lowered immunity, making them more susceptible to disease like pneumonia (Table 4). The public health implication of this study was directed to the child caring practice which was unrealized factor for prevention of pneumonia in current age group. Therefore, parents and implementers on the area need to be sensitized to include the recommended interventions in their activity.

\section{Limitations of the Study}

Diagnosis of pneumonia was based on clinical WHO IMNCI classification guideline, which could introduce misclassification bias. The second limitation could be the limitation due to institution based case control study that can limit the generalizability. Establishing a temporal relationship between the risk factors and the outcome is also impossible in the result reported in the paper.

\section{Conclusion and Recommendations}

This study suggests that childcare practice by a housekeeper, child diarrhea history and household history of ARI in the past fifteen days prior to data collection are strongly associated with increased risk of childhood pneumonia. Based on this conclusion, we recommend strengthening preventative activities for diarrhea, ARI, and promoting the roll of childcare practice through health extension workers.

\section{Acknowledgements}

Author is very grateful to Azeb Girma for her valuable discussion and support during the study.

\section{References}

[1] Black, R.E., Morris, S.S. and Bryce, J. (2003) Where and Why Are 10 Million Children Dying Every Year? Lancet, 361, 2226-2234. http://dx.doi.org/10.1016/S0140-6736(03)13779-8

[2] Rudan, I., Boschi-Pinto, C., Biloglav, Z., Mulholland, K. and Campbell, H. (2008) Epidemiology and Etiology of Childhood Pneumonia. Bulletin of the World Health Organization, 86, 408-416.

http://dx.doi.org/10.2471/BLT.07.048769

[3] WHO (2007) World Health Statistics. Geneva.

[4] Greenwood, B.M., Greenwood, A.M., Bradley, A.K., Tulloch, S., Hayes, R., et al. (1997) Deaths in Infancy and Early Childhood in a Well-Vaccinated, Rural, West African Population. Annals of Tropical Paediatrics, 7, 91-99.

[5] The World Bank Group Africa Region Human Development and Ministry of Health (2005) A Country Status Report on Health and Poverty Addis Ababa, Ethiopia.

[6] Rudan, I., Boschi-Pinto, C., Biloglav, Z. and Mulholland, K. (2008) Epidemiology and Etiology of Childhood Pneumonia. http://www.who.int/bulletin/volumes/86/5/07-048769/en/

[7] Puchalski Ritchie, L.M., Howie, S.R., Arenovich, T., Cheung, Y.B., Weber, M., Moore, S., et al. (2009) Long-Term Morbidity from Severe Pneumonia in Early Childhood in the Gambia West Africa. A Follow-Up Study. International Journal of Tuberculosis and Lung Disease, 13, 527-532.

[8] McNally, L.M., Jeena, P.M., Gajee, K., Thula, S.A., Sturm, A.W., Cassol, S., et al. (2007) Effect of Age, Polymicrobial Disease, and Maternal HIV Status on Treatment Response and Cause of Severe Pneumonia in South African Children. A Prospective Descriptive Study. Lancet, 369, 1440-1451. http://dx.doi.org/10.1016/S0140-6736(07)60670-9

[9] Central Statistics Authority (2011) Ethiopia Demographic and Health Survey, Addis Ababa, Ethiopia.

[10] Abeje, G., Asres, G. and Wubshet, M. (2010) Prevalence and Determinants of Pneumonia among under Five Children in Este Town and Surrounding Rural Kebeles. Unpublished.

[11] Cunha, A.L. (2000) Relationship between Acute Respiratory Infection and Malnutrition in Children under 5 Years of Age. Acta Paediatrica, 89, 608-609.

[12] Yousif, T.K. and Klaheq, B.A. (2006) Epidemiology of Acute Respiratory Tract Infections (ARI) among Children Un- 
der-Five Years Old Attending Tikirit General Teaching Hospital. Middle East Journal of Family Medicine, 4.

[13] Bbaale, E. (2011) Determinants of Diarrhea and Acute Respiratory Infection among Under-Fives in Uganda. Australasian Medical Journal, 4, 400-409. http://dx.doi.org/10.4066/AMJ.2011.723

[14] Azad, K. (2009) Risk Factors for Acute Respiratory Infection (ARI) among Children Under-Five Years in Bangladesh. Journal of Scientific Research, 1, 72-81. http://www.banglajol.info/index.php/JSR

[15] Olaogun, A., Adebayo, A., Ayandiran, O. and Olasode, O. (2006) Effects of Mothers' Socio-Economic Status on the Management of Febrile Condition in Their Under-Five Children in a Resource Limited Setting. BMC International Health and Human Rights, 6, 1. http://dx.doi.org/10.1186/1472-698X-6-1

[16] Deribew, A., Tessema, F. and Girma, B. (2007) Determinants of Under-Five Mortality in Gilgel Gibe Field Research Center, Southwest Ethiopia. Ethiopian Journal of Health Development, 21, 117-124. http://dx.doi.org/10.4314/ejhd.v21i2.10038

[17] Cutts, F., Zaman, S., Enwere, G., Jaffar, S., Levine, O.S., Okoko, J.B., et al. (2005) Efficacy of Nine-Valent Pneumococcal Conjugate Vaccine against Pneumonia and Invasive Pneumococcal Disease in the Gambia: Randomized, Double-Blind, Placebo-Controlled Trial. Lancet, 365, 1139-1146. http://dx.doi.org/10.1016/S0140-6736(05)71876-6

[18] Niessen, L., Ten Hove, A., Hilderink, H., Weber, M., Mulholland, K. and Ezzati, M. (2009) Comparative Impact Assessments of Child Pneumonia Interventions. Bulletin of the World Health Organization, 87, 472-480. http://dx.doi.org/10.2471/BLT.08.050872

[19] Ikeogu, M., Wolf, B. and Mathe, S. (1997) Pulmonary Manifestations in HIV Seropositivity and Malnutrition in Zimbabwe. Archives of Disease in Childhood, 76, 124-128. http://dx.doi.org/10.1136/adc.76.2.124

[20] Ali, M., Asfaw, T., Beyne, H., Byass, P., Shisay, M., Hasibu, M.S. and Pedersen, F.K. (2001) A Community Based Study of Childhood Morbidity in Tigray, Northern Ethiopia. Ethiopian Journal of Health Development, 15, $165-172$. 